\title{
Elaboration of properties of graphene oxide reinforced epoxy nanocomposites.
}

\author{
BARI, P., KHAN, S., NJUGUNA, J. and MISHRA, S.
}

2017

This is a post-peer-review, pre-copyedited version of an article published in International Journal of Plastics Technology. The final authenticated version is available online at: https://.doi.org/10.1007/s12588-017-9180-

9. This pre-copyedited version is made available under the springer terms of reuse for AAMs. 


\title{
Elaboration of properties of graphene oxide reinforced epoxy nanocomposites
}

\author{
Pravin Bari $^{1}$, Samrin Khan ${ }^{1}$, James Njuguna², Satyendra Mishra ${ }^{1 *}$ \\ ${ }^{1}$ University Institute of Chemical Technology, North Maharashtra University, \\ Jalgaon-425001, Maharashtra, India
}

${ }_{2}^{2}$ School of Engineering, Robert Gordon University, Riverside East, Aberdeen, AB10 7GJ, United Kingdom

\begin{abstract}
In this research work, properties of graphene oxide (GO) based epoxy nanocomposites, prepared via the solution blending method, are elaborated. Different loadings (0.1$0.5 \mathrm{wt} \%$ ) of GO were added into epoxy resin, and their effects were studied on their surface reaction, morphology, mechanical and thermal properties. It was found that a chemical modification, layer expansion and dispersion of filler within the epoxy matrix resulted in an improved interface bonding between the GO and epoxy matrix. The optimum amount of graphene nanostructures can be useful to improve the properties of epoxy nanocomposites for applications in adhesives to automotive.
\end{abstract}

\section{Keywords}

Graphene Epoxy Nanocomposites Preparation Mechanical and thermal properties

\section{Introduction}

Graphene, new carbon material, based nanocomposites have attracted considerable attention and have shown an immense interest due to their unique properties [1] It has a wide potential applications in energy related systems, mainly because of its unique atom-thick two dimensional structure $[\underline{2}, \underline{3}]$, high thermal conductivity $[\underline{4}, \underline{5}]$, 
mechanical stiffness $[\underline{6}, \underline{7}]$, electronic transport properties $[\underline{8}, \underline{9}, \underline{10}, \underline{11}]$, optical and chemical performance [12] as well as multi layer hybrid nano structures [13]. However, the stronger hydration and easier dispersion of GO in water are observed; while GO was prepared by the Modified Hummers method [14, 15, 16]. GO prepared from graphite flakes can be used on a large scale for preparation of graphitic films and as a binder for carbon products [17]. Silva et al. [18] concluded from their experiment that the graphene/epoxy nanocomposite shows rise in working temperature and durability of composite and also observed improvement in mechanical properties. Sharmila et al. [19] reported that the combination of good processing properties with enhanced mechanical and dielectric properties makes GO great candidate to develop multifunctional polymer nanocomposites which has sought extensive application in electromagnetic interference shielding (EMI), conductive adhesives and for thermal conductivity enhancement. GO was also used as modifying agent and graphene layer also prepared by oxidation [20, 21]. Fracture toughness of carbon-graphene/epoxy hybrid nanocomposites has also been studied. Graphene has two dimensional structure can be used in its both forms, i.e. in its oxidized form and in its reduced form [22, $\underline{23}]$. As the oxidized form of graphene have functionality linked up and it provides insulating characteristics, while the reduced form of graphene contains no functionality or some amount of functionality $[\underline{24}, \underline{25}, \underline{26}]$. Graphene can be synthesis by chemical vepor deposition and arc discharge method [27, 28]. This can provide to it conducting nature used for increasing conductivity of the matrix in which it is incorporated. It can be said that the graphene as nanofiller has an application from insulator to conductor [29, $\underline{30]}$. Graphene made of atomically thin carbon sheets also improves physical properties of host polymers [푸 $\underline{32}, \underline{33}, \underline{34}]$.

Epoxy resin is considered one of the most versatile thermoset materials, which has applications in several fields due to its excellent adhesion, electrical insulating, mechanical and thermal properties, as well as, chemical and heat resistance. However, epoxy resins are generally brittle which restrict their applications. Hawkins et al. [35, 36] studied the fracture toughness and strain energy behavior of carbon-graphene/epoxy hybrid nanocomposites. GO-epoxy based nanocomposites also possess the flexural behavior. [37]. Ribeiro et al. [38] studied the glass transition improvement in grapheneepoxy composites. Multi-nanostructured (clay and graphene platelets) reinforced epoxy nanocomposites have been also studied by Zaman et al. [39]. Mechanical and thermal 
properties of epoxy composites containing GO and liquid crystalline epoxy have also been studied [40].

In the present work we have focused to reinforce the GO in epoxy resin by solution blending method using acetone as diluent for epoxy. The resulting epoxy nanocomposites were characterized by FESEM, FTIR, XRD, EDX and DSC. Different properties were studied to probe the effect of the nanofillers on the mechanical and thermal properties of the composites. The elemental mapping of the composites was done to understand the GO dispersion in epoxy.

\section{Experimental}

\section{Materials}

Graphite powder (98\%), from Lobel Chemical, Ortho-phosphoric acid $\left(\mathrm{H}_{3} \mathrm{PO}_{4}, 85 \%\right)$ and Hydrogen Peroxide $\left(\mathrm{H}_{2} \mathrm{O}_{2}, 30 \%\right)$ were purchased from Lobel chemical and Merck specialist Pvt. Ltd. Mumbai, India; Sulfuric acid $\left(\mathrm{H}_{2} \mathrm{SO}_{4}, 97 \%\right)$, Potassium permanganate $\left(\mathrm{KMnO}_{4}, 99.9 \%\right)$, petroleum ether, Hydrazine Hydrate, Acetone and Ethanol (AR grade) were purchased from Rankem Thane, Maharashtra, India. Reactive diluents RD-113, Epoxy resin grade YD128 of EEW-189.5, viscosity 11,000-14,000 cp were procured from Aditya Birla Groups Mumbai, India. Curing agent Diethylene Triamine (DETA purity) was purchased from s. d. Fine. Chemicals Limited, Mumbai, India.

\section{Synthesis}

\section{Preparation of GO}

Graphite powder $(5.0 \mathrm{gm})$ was mixed into the solution of concentrated $\mathrm{H}_{2} \mathrm{SO}_{4}$ and $\mathrm{H}_{3} \mathrm{PO}_{4}$ taken in 9:1 ratio (600:66.66 mL). Sulfuric acid intercalated GO has also been prepared [23]. Meanwhile, 8-9 time weight equivalent $\mathrm{KMnO}_{4}(30.0 \mathrm{gm})$ powder was also added to graphite mixed solution. This reaction mixture was then heated in three necked flask fitted with water cooled condenser having temperature below $50{ }^{\circ} \mathrm{C}$ and allowed to stir continuously for $12 \mathrm{~h}$. The reaction mixture was cooled to room temperature and then kept in ice bath after the addition of $30 \% \mathrm{H}_{2} \mathrm{O}_{2}$. Resulting suspension was filtered through polyester fiber cloth and remaining filtrate was centrifuged at $4000 \mathrm{rpm}$. The supernatant solution was decanted and residual solid 
material was washed with water, $30 \% \mathrm{HCl}$, distilled water and finally with ethanol. The solid material was coagulated with $200 \mathrm{~mL}$ of PET ether and vacuum-dried overnight at room temperature. In this manner several batches were carried out for bulk preparation of GO.

\section{Preparation of graphene-epoxy nanocomposites}

Solution blending method was used for nanocomposite preparation of graphene-epoxy nanocomposites. Graphene oxide was taken into varying amounts from 0.1 to $0.5 \mathrm{wt} \%$. Total $55 \mathrm{~g}$ was the amount of all compositions of epoxy nanocomposites. Epoxy resin was taken into prescribed amount (Table 1 ) then acetone was added into the resin to lower down its viscosity. Then GO was sonicated for $30 \mathrm{~min}$. The GO dispersion was mixed into the resin under high speed for $45 \mathrm{~min}$ and mixed with ethanol in the said ratio then kept it at $80{ }^{\circ} \mathrm{C}$ in an oil bath till the solvent evaporation. Then the mixture was sonicated for $30 \mathrm{~min}$ and then $10 \mathrm{phr}$ DETA $(5.56 \mathrm{~g}$ ) was added to the mixture (Fig. 1). The mixture was poured into the mould, degassed for $1 \mathrm{~h}$ and then cured at room temperature for 2-3 days. Samples were cut for further mechanical and thermal testing.

Table 1

Amount of ingredients required for preparation of epoxy nanocomposites

Sr. GO (wt.\%) in resin Epoxy resin (wt.\%) in Amount of Amount of No. nanocomposites resin nanocomposites $\quad$ GO $(\mathrm{gm}) \quad$ resin $(\mathrm{gm})$
10.1
99.9
0.055
54.975

20.2

99.8

0.110

54.890

30.3

99.7

0.165

54.835

$4 \quad 0.4$

99.6

0.220

54.780

$5 \quad 0.5$

99.5

0.275

54.725 


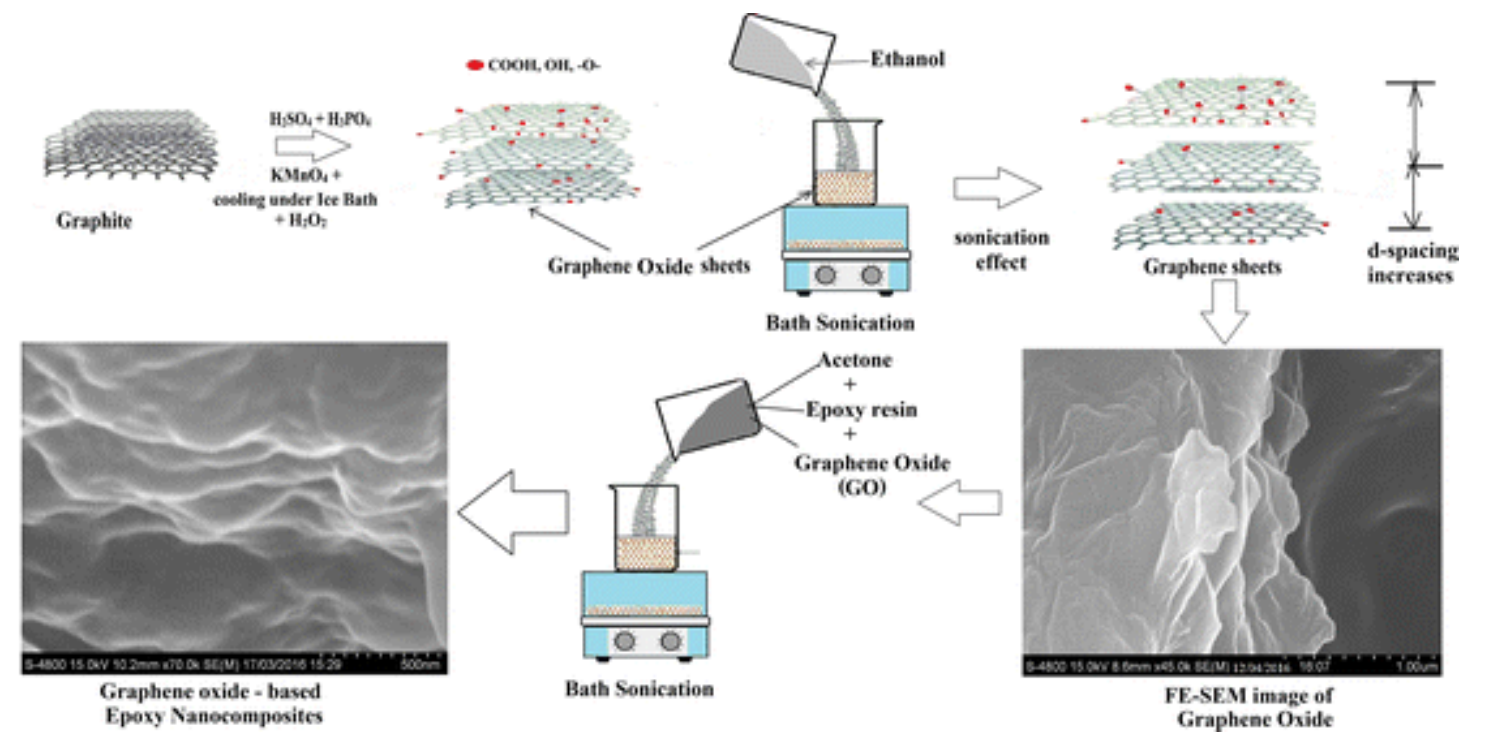

Fig. 1

Schemetic diagram of preparation of graphene oxide and GO to epoxy/GO composite

\section{Characterization}

\section{Field emission-scanning electron microscopy (FE-SEM)}

The surface morphology of the epoxy nanocomposites was examined using a scanning electron microscope (SEM) (S4800, Type II, Hitachi, Tokyo, Japan) at an operation voltage of $10 \mathrm{keV}$ and a pressure of 0.98 Torr. The epoxy nanocomposite specimens were coated with gold and mounted on the specimen stub before analysis.

\section{Fourier transform infrared (FTIR) spectroscopy}

Samples of the GO and epoxy nanocomposites were finely divided and dispersed in a $\mathrm{KBr}$ powder for analysis. FTIR spectrophotometer (8400, Shimadzu, Tokyo, Japan) was used to obtain spectra and to comprehend the bond formation between filler and epoxy resin. Total 45 scans were taken for each nanocomposite sample recorded at $4000-400 \mathrm{~cm}^{-1}$ with resolution of $4 \mathrm{~cm}^{-1}$ in the transmittance mode.

\section{Mechanical analysis}

Tensile tests were performed using a Universal Testing Machine (INSTRON 5582, Buckinghamshire, UK). The tensile tests were conducted according to ASTM D638. Testing was carried out at room temperature with the crosshead speed of $4 \mathrm{~mm} / \mathrm{min}$, 
span length of $40 \mathrm{~mm}$ and a load of $500 \mathrm{~kg}$. The mean value of total five specimens was taken to report tensile strength and tensile modulus.

\section{X-ray diffraction analysis}

X-ray diffraction (XRD) analysis was carried out by X-ray diffractometer, (BRUKERS

D8, Coventry, Germany) within the $2 \theta$ range of $20^{\circ}-80^{\circ}$ with $\mathrm{CuK} \alpha_{1}$ radiation $(\lambda=1.5404 \AA)$, operating voltage of $40 \mathrm{keV}$ and a current of $40 \mathrm{~mA}$. A dwell time was kept $2 \mathrm{~s}$ per step. The crystalline phases and their relative contents in the materials were quantitatively obtained by location and number of diffraction peak and relative intensity of XRD pattern.

\section{Thermal tests}

Perkin Elmer TGA-4000 was used for thermal analysis from room temperature to $800{ }^{\circ} \mathrm{C}$ at the rate of $5{ }^{\circ} \mathrm{C} / \mathrm{min}$, under a nitrogen flow rate of $20 \mathrm{ml} / \mathrm{min}$. Thermo gravimetric analyzer was used to investigate the thermal decomposition behavior of composites. Tests were performed under nitrogen at a scan rate of $20{ }^{\circ} \mathrm{C} / \mathrm{min}$ in a programmed temperature range of $20-800{ }^{\circ} \mathrm{C}$. Approximately, $8 \mathrm{mg}$ of sample was used for each run. The change in weight was recorded with respect to temperature. Derivative peak temperature $(D T p)$ was considered as the maximum temperature acquired from the differentiation of the weight change as a function of time.

Phase transitions of nanocomposites were investigated on a differential scanning calorimeter (DSC60, Shimadzu, Tokyo, Japan) over the temperature range of 35$450{ }^{\circ} \mathrm{C}$ at heating rate of $10{ }^{\circ} \mathrm{C} / \mathrm{min}$ under nitrogen atmosphere.

\section{Results and discussion}

\section{FTIR spectra}

Figure $\underline{2}$ shows the FTIR spectra of epoxy-GO nanocomposites with GO loadings from 0.1 to $0.5 \mathrm{wt} \%$. The FTIR analysis was performed to confirm the interaction of graphene oxide with epoxy. 


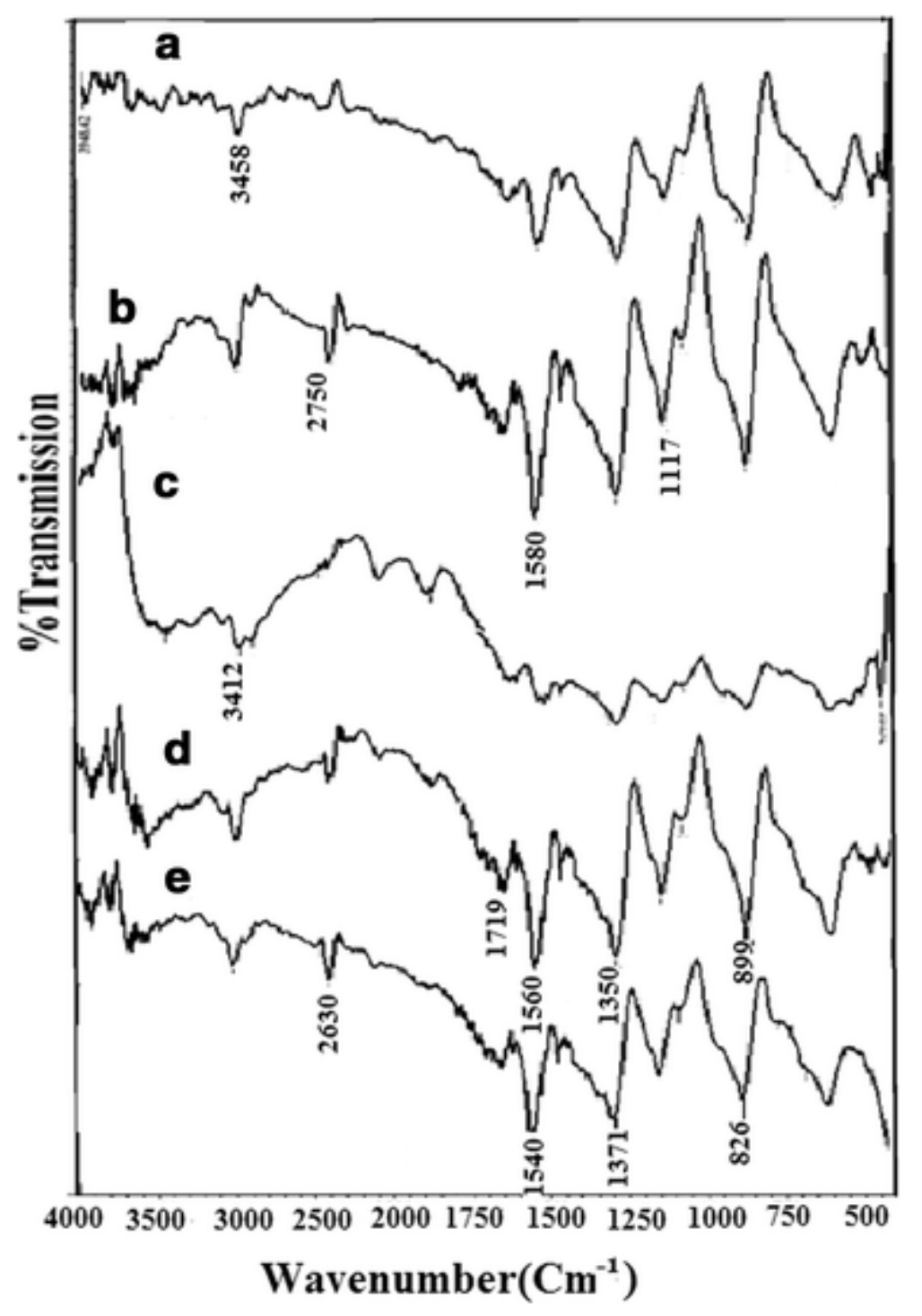

Fig. 2

FTIR spectra of GO-epoxy nanocomposites a 0.5 , b $0.4, \mathbf{c} 0.3$, d 0.2 , e $0.1 \mathrm{wt} \%$ of GO

The characteristic features in the FT-IR spectrum of GO are absorption bands corresponding to $\mathrm{C}=\mathrm{O}$ carboxyl $1721 \mathrm{~cm}^{-1}$, the $\mathrm{C}-\mathrm{OH}$ stretching at $1371 \mathrm{~cm}^{-1}$, and the C-O stretching at $1117,3412 \mathrm{~cm}^{-1}$ is due to the stretching vibration of hydroxyl group. The absorption at $899 \mathrm{~cm}^{-1}$ is due to the epoxy group, It confirms that the surface of graphite oxide was successfully reinforced.

Compared to natural graphite, graphite oxide and graphene oxide exhibit two peaks at 1560 and $1719 \mathrm{~cm}^{-1}$, which are attributed to the benzene ring and carboxyl groups, and one peak at $1223 \mathrm{~cm}^{-1}$ is resulted from the $\mathrm{C}-\mathrm{O}$ group and the peaks at 826,934 and $1027 \mathrm{~cm}^{-1}$ are caused by the epoxide group. Since the raw graphite used in the study was treated with acid, strong absorptions of acid were expected. The characteristic 
bands of raw graphite showed absorption at $2327 \mathrm{~cm}^{-1}$ and a band between 3304 and $3500 \mathrm{~cm}^{-1}$ attributed to the presence of $-\mathrm{OH}$ group; absorptions at 1650 and $873 \mathrm{~cm}^{-1}$ correspond to the stretching vibration of $-\mathrm{C}=\mathrm{O}$ and $-\mathrm{C}-\mathrm{O}-$, respectively, which imply the existence of carboxyl group. The higher level of improvement offered by GO is attributed to the strong interaction of graphene sheets with epoxy because the covalent bonds between the carbon atoms of graphene sheets are much stronger than other layered nanomaterial such as silicon-based clay.

\section{Morphological properties}

Figure $\underline{3}$ shows FE-SEM micrographs of GO with formation of curved nanosheets. Scientists, nanotechnologists have reported the flexible, high strength, mechanically robust graphene with nanoscale dimensions.
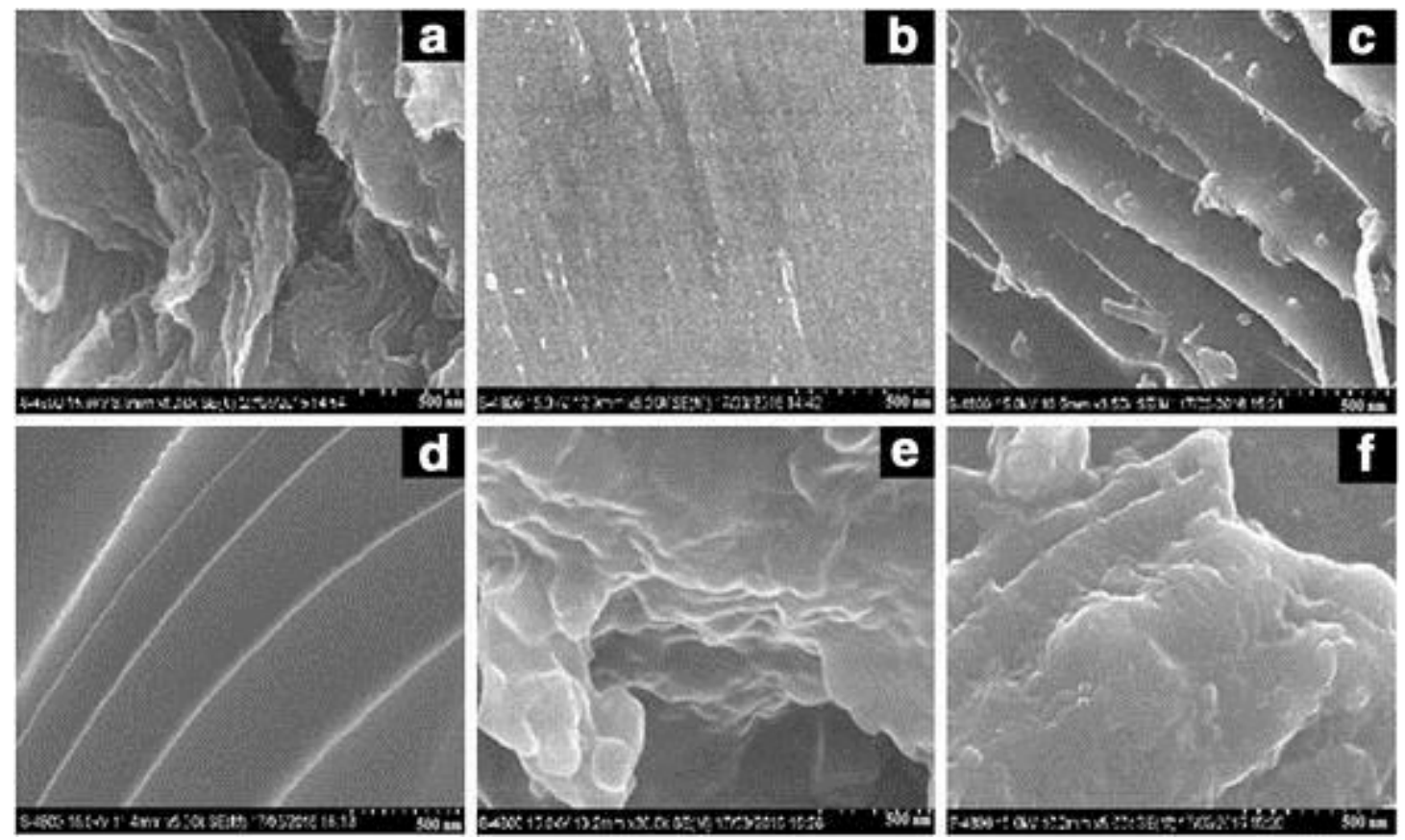

Fig. 3

FE-SEM images of a GO, b virgin epoxy, c 0.2 wt $\%$ GO/E, d 0.3 wt $\%$ GO/E, e 0.4 wt $\%$ $\mathrm{GO} / \mathrm{E}$ and $\mathbf{f} 0.5 \mathrm{wt} \% \mathrm{GO} / \mathrm{E}$ composites

Figure $\underline{3} \mathrm{c}-\mathrm{f}$ shows GO based epoxy nanocomposites. To understand the influence of added GO on the mechanical properties of the epoxy nanocomposites, the fracture surfaces of the samples after impact tests were characterized with FESEM. A smooth surface (Fig. $\underline{3} b$ ) was observed in the virgin epoxy sheet. The fracture surfaces of the $\mathrm{GO} /$ epoxy nanocomposites appeared rougher and more varied in comparison to virgin 
epoxy, indicating that higher fracture energy may require. However, the sample with excessive GO loading, (0.5 wt \%), exhibited an agglomeration of GO and some defects in the matrix. SEM micrographs of the virgin epoxy, GO and their nanocomposites indicated a better dispersion of the filler. A large agglomeration of graphene, which leads to a disruption in the uniformity of the the epoxy nanocomposite. Morphologies also confirm that good adhesion was obtained between the graphene and the epoxy based nanocomposites. To understand the dispersion behavior, the elemental mapping was done by EDX. Table given in Fig. 4 shows the elemental contents of the different composites. It was observed from the resuts that $0.3 \mathrm{wt} \%$ of GO shows better dispersion amongst all composites.

Fig. 4

Carbon and oxygen mapping of GO: epoxy composites containing a $0.2 \mathrm{wt} \%$, b $0.3 \mathrm{wt} \%$ and $\mathbf{c} 0.4 \mathrm{wt} \% \mathrm{GO}$

\section{Crystallinity}

Figure $\underline{5}$ shows the XRD patterns of GO based epoxy nanocomposites. Natural graphite exhibits a strong and sharp peak at $26.5^{\circ}$, indicating a highly ordered structure. The Virgin epoxy resin exhibits only one broad peak at $18.5^{\circ}$, reflecting its $65.6 \%$ amorphous feature (Table 2 ). Interestingly, the nanocomposite also has this peak only and does not exhibit any other peak, indicating an exfoliated feature of graphene oxide in epoxy matrix.

Fig. 5

XRD images of epoxy nanocomposites containing different weight $\%$ of ( $a$ ) GO

Table 2

Change in enthalpy, degradation temperature of GO based Epoxy nanocomposites 


\section{Thermal analysis}

XRD

analysis

\section{Epoxy}

$\begin{array}{lll}\text { nanocomposites } & \text { Temperature }\left({ }^{\circ} \mathrm{C}\right) & \text { Change in } \\ \text { (wt.\% of GO) } & \text { enthalpy } \Delta \mathrm{H} \%\end{array}$

Onset Endset Peak Degradation in $\mathrm{KJ} / \mathrm{gm}$ Crystallinity

(Heat in $\mathbf{m J}$ )

\begin{tabular}{|c|c|c|c|}
\hline 0.5 & 318.42339 .2 & $327.19335-365$ & 1.09 \\
\hline 0.4 & 315.88335 .88 & $326.38330-355$ & 4.18 \\
\hline 0.3 & 313.50336 .28 & $323.78325-355$ & 4.69 \\
\hline 0.2 & 309.63333 .81 & $318.46320-345$ & 1.38 \\
\hline 0.1 & 324.91338 .27 & $333.40335-360$ & 1.51 \\
\hline 0.0 & $325.9 \quad 342.69$ & $333.9 \quad 340-390$ & 1.33 \\
\hline
\end{tabular}

Table $\underline{2}$ indicates $\%$ crystallinity of the GO based epoxy nanocomposites. It can be clearly seen that $\%$ crystallinity increases with increasing the GO in the epoxy nanocomposites. On comparison, the GO epoxy composites had maximum 52.3\% crystallinity.

\section{Mechanical properties}

Figure $\underline{6}$ shows that Tensile strength of GO nanocomposites increases with increase in filler (GO) amount from 0.1 to $0.4 \mathrm{wt} \%$. But tensile strength decreases in case of $0.5 \mathrm{wt} \%$ due to agglomeration of filler. The virgin epoxy sheets show the least (19 MPa) tensile strength, while highest (51 MPa) for the composites having $0.4 \mathrm{wt} \%$ of GO followed by $41 \mathrm{MPa}$ for $0.5 \mathrm{wt} \% \mathrm{GO}$ filled composites.

Fig. 6

Tensile strength And Young modulus of GO-Epoxy composites 
Like tensile strength, the vaues of young's modulus were also recorded to increase up to $750 \mathrm{MPa}$ at $0.4 \mathrm{wt} \%$ of GO in epoxy (Fig. $\underline{6}$ ). The composite with $0.5 \mathrm{wt} \%$ of GO shows $675 \mathrm{MPa}$, which is slightly less than the $0.4 \mathrm{wt} \%$ of GO composite. However virgin epoxy shows only $367 \mathrm{MPa}$. Thus dimensional stability of the $0.4 \mathrm{wt} \%$ filled composite is approximately two times greater than the virgin epoxy.

On recording the $\%$ elongation of the composites, the $0.4 \mathrm{wt} \%$ filled composite illustrates least (2.94\%) elongation (Fig. 7). A comparison of results gives that the $\%$ elongation of composites is found to drop significantly, at $0.4 \mathrm{wt} \%$ loading of GO.

\section{Fig. 7}

$\%$ Elongation of GO/Epoxy Composites at different wt $\%$ of GO

The addition of fillers (GO) to the epoxy matrix also effects the impact strength and hardness relative to the neat epoxy for the $0.0-0.5 \mathrm{wt} \%$ of GO-epoxy based nanocomposites. The impact strength and hardness of the composites are shown in Fig. $\underline{8}$. The results of the impact strength were found to increase up to $0.4 \mathrm{wt} \%$ addition of GO in epoxy having highest value as $89 \mathrm{~J}$. The highest loading $(0.5 \mathrm{wt} \%)$ of GO in epoxy showed only $79 \mathrm{~J}$, which is less than the $0.4 \mathrm{wt} \%$ filled GO. On comprehensive comparison of the results, the epoxy without GO had least $(67 \mathrm{~J})$ amongst all compositions.

Fig. 8

Impact Strength and Hardness of GO/Epoxy Composites at different wt\% of GO

Like other mechanical properties, the hardness was also found to increase with increase in filler content up to $0.4 \mathrm{wt} \%$ and decreased thereafter. The values of hardness are recorded as $75,78,79,80,84$ and 79 for virgin epoxy $0.1,0.2,0.3,0.4$ and $0.5 \mathrm{wt} \%$ GO filled composites respectively. Thus the $0.4 \mathrm{wt} \%$ is the optimum amount to get maximum improvement in the mechanical properties.

The reason behind improvement at $0.4 \mathrm{wt} \%$ is that the GO sheets dispersed uniformly intercalated within the epoxy chains. The mechanical properties (\% elongation, tensile 
strength, impact strength and young's modulus) of the GO-epoxy nanocomposites possess a greater variability than those of the GO-epoxy nanocomposites up to certain loading level. This is likely due to the greater difficulty in uniformly dispersing the more graphene sheets throughout the epoxy matrix. It is already reported in the text that the addition of nanofillers to the epoxy matrix, up to $0.4 \mathrm{wt} \% \mathrm{GO}$ exhibites highest mechanical properties. Further addition of GO results decrement in mechanical properties, which is due to the presence of large aggregates and some defects of the nanoreinforcements formed on the surface during sample preparation as well.

\section{Thermal properties}

DSC curves of the GO/epoxy mixtures are shown in Fig. $\underline{9}$ and Table $\underline{2}$ which show the thermal behavior of neat epoxy and epoxy nanocomposites with different GO contents. All samples showed a single exothermic peak at a temperature, more than $300{ }^{\circ} \mathrm{C}$, originating from the decomposition of functional groups on GO in the epoxy-based composites. It is observed from the results that there were no much variations in onset, end set and peak temperatures of the GO based epoxy nanocomposites. 


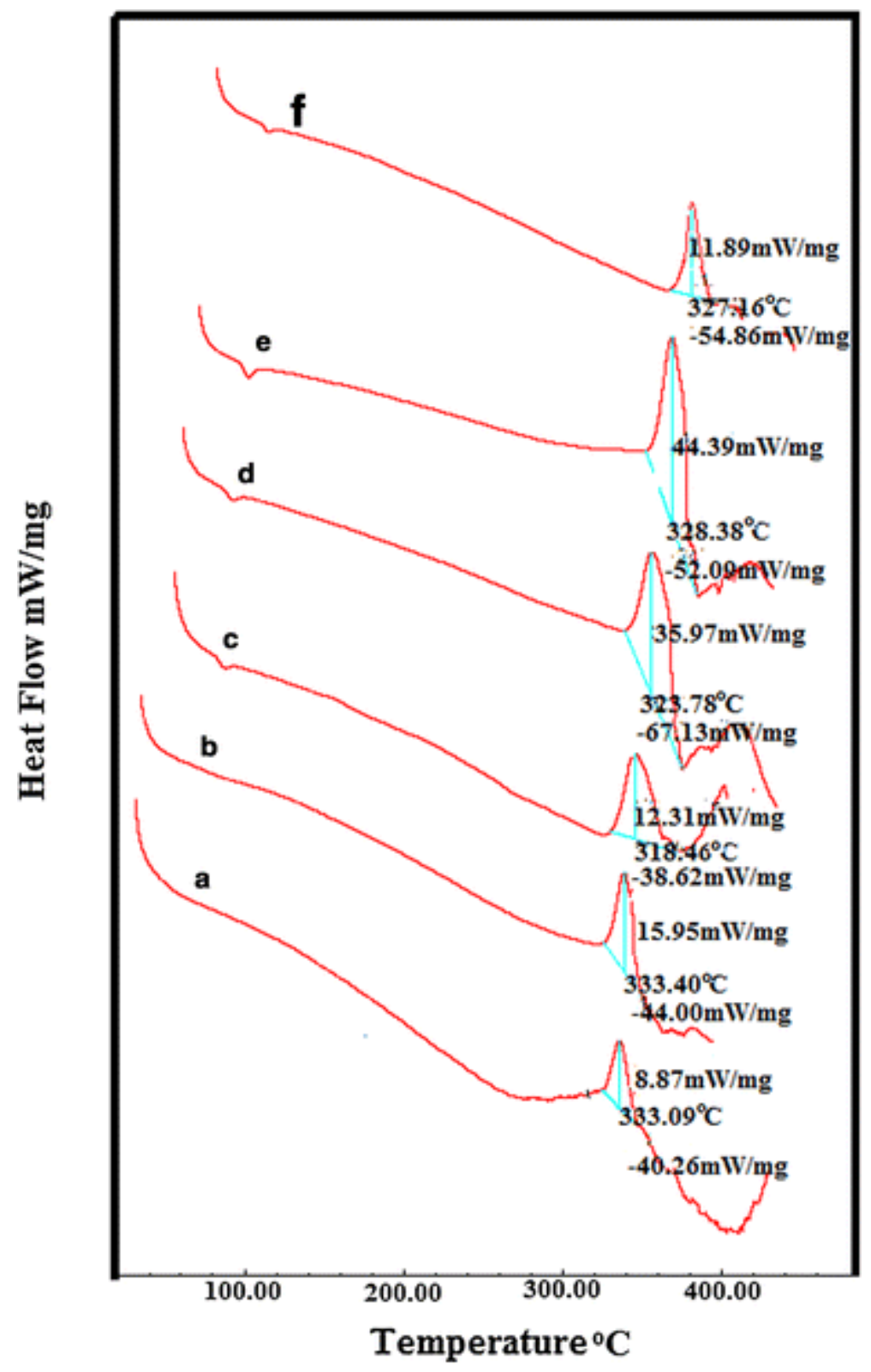

Fig. 9

DSC analysis of virgin epoxy (a), $0.1 \mathrm{wt} \%$ (b), $0.2 \mathrm{wt} \%$ (c), $0.3 \mathrm{wt} \%$ (d), $0.4 \mathrm{wt} \%$ (e), and $0.5 \mathrm{wt} \%$ (f) GO: Epoxy composites

The main exothermic peaks of GO/epoxy nanocomposites were observed to be at a higher temperature than those for neat-epoxy composites. It was confirmed that this was due to the steric hindrance effect on the curing process with the addition of GO particles. The higher volume fraction of GO increased the surface area in contact with the epoxy matrix, which could anchor the chain mobility [38].

Representative DSC curves for the virgin epoxy and the nanocomposites with concentrations of 0.1 to $0.5 \mathrm{wt} \% \mathrm{GO}$ are shown in Fig. $\underline{9}$. It was reported that the glass 
transition region is larger for the composites than for the neat epoxy, which is associated with the filler effect of broader the segmental motion range. A clear increase in the $\mathrm{Tg}$ of $10-20^{\circ} \mathrm{C}$ of the composites in respect to the neat epoxy was reported. Similar increases in the Tg were observed for the nanocomposites produced with an epoxy and different types of modified graphene. However, it is important to note that graphene fillers possessed a similar tendency to increase the glass transition temperature in the case of the materials $[\underline{38}, \underline{39}]$.

As reported earlier that the thermal stability of the composites is effected by the treatment and addition of fillers $[\underline{41}, \underline{42}, \underline{43}]$, the GO also effects the thermal decomposition behavior of the epoxy. The primary wt. loss of $\mathrm{GO}$ from $150{ }^{\circ} \mathrm{C}$ is mainly due to the decomposition of the oxygen-functional groups attached on the GO. However the results of thermogravimetric analysis indicate that the composites are much thermally stable than the GO; more over there is very less difference in degradation of all composites. However $0.4 \mathrm{wt} \%$ GO containing composite shows higher thermal stability amongst them; while cured virgin epoxy shows highest thermal stability depicting wt. loss from $350{ }^{\circ} \mathrm{C}$ onwards (Fig. 10). The early wt. loss in composites is due to the removal of moisture and remaining functional groups present in GO as mentioned earlier.

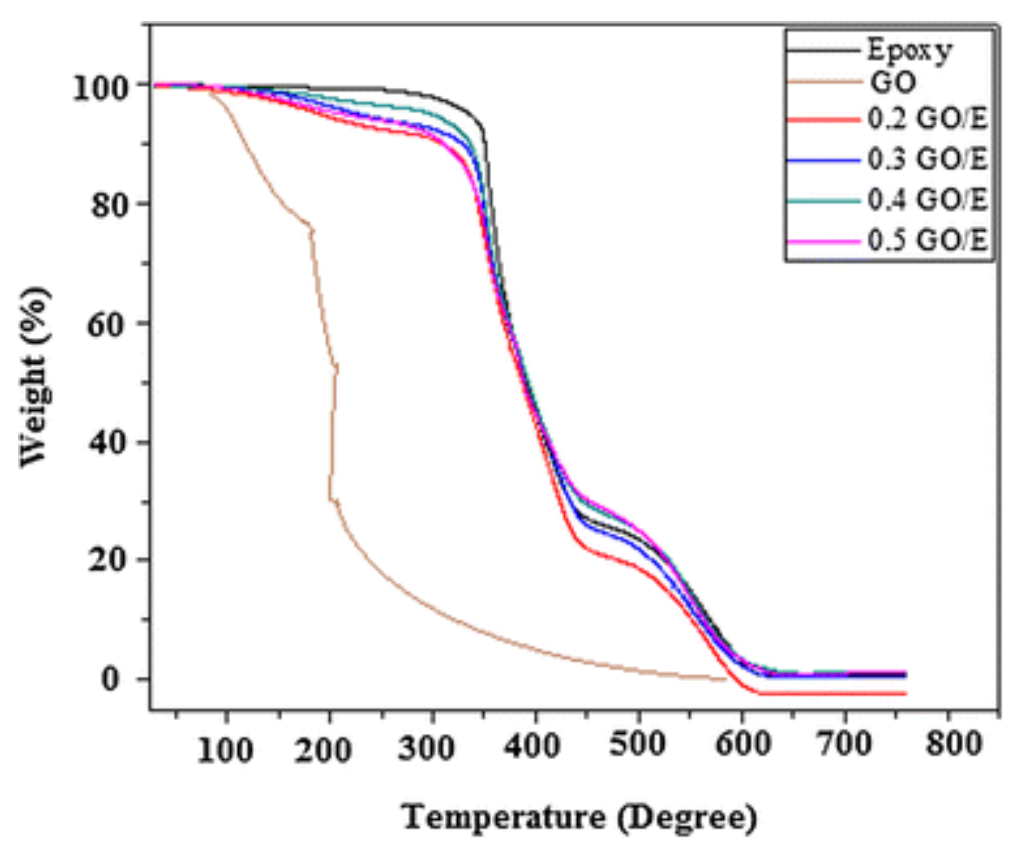

Fig. 10

Thermogravimetric analysis of epoxy: RGO composites 


\section{Acknowledgements}

Authors are thankful to DST, Govt. of India and UKIERI, British Council for providing financial assistance (Project No. DST/INT/UK/P-108/2014) to carry out this research work.

\section{References}

1. Kim HS, Abdala AA, Macosko WC (2010) Graphene/polymer nanocomposites. Macromolecules 43:6515

2. Sun Y, Shi G (2013) Graphene/polymer composites for energy applications. J Polym Sci B Polym Phys 51:231

3. Zhao X, Zhang Q, Chen D (2010) Enhanced mechanical properties of graphene-based poly(vinyl alcohol) composites. Macromolecules 43:2357-2363

4. Balandin AA, Ghosh S, Bao W, Calizo I, Teweldebrhan D, Miao F, Lau CN (2008) Superior thermal conductivity of single-layer graphene. Nano Lett 8(3): 902-907

5. Tung TT, Karunagaran R, Tran DNH et al (2016) Engineering of graphene/epoxy nanocomposites with improved distribution of graphene nanosheets for advanced piezo-resistive mechanical sensing. J Mater Chem C 4:3422

6. Min K, Aluru NR (2011) Mechanical properties of graphene under shear deformation. Appl Phys Lett 98:013113

7. Qi B, Lu SR, Xiao XE, Pan LL, Tan FZ, Yu JH (2014) Enhanced thermal and mechanical properties of epoxy composites by mixing thermotropic liquid crystalline epoxy grafted graphene oxide. Express Polym Lett 8(7):467-479

8. Hansora DP, Shimpi NG, Mishra S (2015) Graphite to graphene via graphene oxide: an overview on synthesis, properties, and applications. JOM 67(12):2855-2868

9. Rana VK, Choi MC, Kong JY, Kim GY, Kim MJ, Kim SH, Mishra S, Singh RP, Ha CS (2011) Synthesis and drug delivery behavior of chitosan functionalized graphene oxide hybrid nano sheets. Macromol Mater Eng 296(2):131 
10. Rana VK, Akhtar S, Chatterjee S, Mishra S, Singh RP, Ha CS (2014) Chitosan and Chitosan-Co-Poly ( $\varepsilon$-Caprolactone) grafted multiwalled carbon nanotube transducers for vapour sensing. J Nanosci Nanotechnol 14(3):2425-2435

11. Jain R, Mishra S (2016) Electrical and electrochemical properties of graphene modulated through surface functionalisation. RSC Adv $6: 27404-27415$

12. Liu Z, Wang Y, Zhang X, Xu Y, Chen Y, Tian J (2009) Nonlinear optical properties of graphene oxide in nanosecond and picosecond regimes. Appl Phys Lett 94:021902

13. Khobaragade PS, Hansora DP, Naik JB, Njuguna J, Mishra S (2016) Preparation and analyasis of multilayer hybrid nanostructures. Appl Clay Sci 132-133:668-674

14. Shimpi NG, Mishra S, Hansora DP, Savdekar U (2013) Indian Patent 3179/MUM/2013.

http://ipindia.nic.in/ipr/patent/journal_archieve/journal_2013/pat_arch_ 102013/official_journal_25102013_part_i.pdf

15. Marcano DC, Kosynkin DV, Berlin JM, Sinitskii A, Sun Z, Slesarev A, Alemany LB, Lu W, Tour JM (2010) Improved synthesis of graphene oxide. ACS Nano 4(8):4806-4814

16. Paulchamy B, Arthi G, Paulchamy Lignesh BD et al (2015) A simple approach to stepwise synthesis of graphene oxide nanomaterial. J Nanomed Nanotechnol. doi: 10.4172/2157-7439.1000253

17. Jung I, Dikin DA, Piner RD, Ruoff RS (2008) Tunable electrical conductivity of individual graphene oxide sheets reduced at low temperatures. Nano Lett 8:4283

18. Silva LCO, Silva GG, Ajayan PM, Soares BG (2015) Long-term behavior of epoxy/graphene-based composites determined by dynamic mechanical analysis. J Mater Sci 50:6407-6419 
19. Sharmila BTK, Nair AB, Abraham BT, Beegum SPM, Thachil ET (2014) Polymer 55:3614-3627

20. Bari P, Lanjewar S, Hansora DP, Mishra S (2016) Influence of the coupling agent and graphene oxide on the thermal and mechanical behavior of tea dust-polypropylene composites. J Appl Polym Sci $133: 3614-3627$

21. Wojtoniszak M, Mijowska E (2012) Controlled oxidation of graphite to graphene oxide with novel oxidants in a bulk scale. J Nanopart Res $14: 1248$

22. Loryuenyong V, Totepvimarn K, Eimburanapravat P, Boonchompoo W, Buasri A (2013) Preparation and characterization of reduced graphene oxide sheets via water based Exfoliation and reduction method. Adv Mater Eng. doi:10.1155/2013/923403

23. Hong Y, Wang Z, Ji X (2013) Sulfuric acid intercalated graphite oxide for graphene preparation. Sci Rep 3:3439

24. Zhu Y, Murali S, Cai W, Li X, Suk JW, Potts JR, Ruoff RS (2010) Graphene and graphene oxide: synthesis, properties, and applications. Adv Mater 22:3906-3924

25. Singh V, Joung D, Zhai L, Das S, Khondaker SI, Seal S (2011) Graphene based materials Past, Present and future. Prog Mater Sci 56:1178-1271

26. Li Z, Wang R, Young R, Deng L, Yang F, Hao L, Giao W, Liu W (2013) Control of the functionality of graphene oxide for its application in epoxy nanocomposites. Polymer 54(23):6437-6446

27. Vlassiouk I, Fulvio P, Meyer H, Lavrik N, Dai S, Datskos P, Smirnov S (2013) Large scale atmospheric pressure chemical vapour deposition of graphene. Carbon 54:58-67

28. Subrahmanyam KS, Panchakarla LS, Govindaraj A, Rao CNR (2009) Simple method of preparing graphene flakes by an arc-discharge method. J Phys Chem C 113:4257-4259

29. Mao HY, Lau YH, Lin JD, Zhong S, Wee A, Chen W (2013) Manipulating the electronic and chemical properties of graphene via molecular functionalisation. Prog Surf Sci 88:132-159

30. Shimpi NG, Hansora DP, Yadav R, Mishra S (2015) Performance of hybrid nanostructured conductive cotton threades as LPG sensor at 
ambient temperature: preparation and analysis. RSC Adv 5:9925399269

31. Galpaya D, Wang M, Liu M, Motta N, Waclawik E, Yan C (2012) Recent advances in fabrication and characterization of graphenepolymer nanocomposites. Graphene 1:30-49

32. Yoonessi M, Shi Y, Scheiman DA, Colon ML, Tigelaar DM, Weiss RA, Meador MA (2012) ACS Nano 6(9):7644

33. Khobragade PS, Hansora DP, Naik JB, Njuguna J, Mishra S (2017) Effect of multilayered nanostructures on the physico-mechanical properties of ethylene vinyl acetate-based hybrid nanocomposites. Polym Compo. doi:10.1002/pc.24371

34. Khobragade PS, Hansora DP, Naik JB, Njuguna J, Mishra S (2017) Physico-mechanical properties of nano polystyrene (nPS) decorated graphene oxide (GO)-epoxy composites. Polym Inte. doi:10.1002/pi.5392

35. Hawkins DA Jr, Haque A (2014) Fracture toughness of carbongraphene/epoxy hybrid nanocomposites. Proc Eng 90:176-181

36. Hawkins DA Jr, Haque A (2015) Strain energy release rate and mode-I delamination growth in carbon-graphene/epoxy hybrid nanocomposites. Proc Eng 105:829-834

37. Lee SY, Chong MH, Park M, Kim HY, Park SJ (2014) Effect of chemically reduced graphene oxide on epoxy nanocomposites for flexural behaviors. Carbon Lett 15(1):67-70

38. Ribeiro H, Silva WM, Rodrigues MTF, Neves JC, Paniago R, Fantini C, Calado HDR, Seara LM, Silva GG (2013) Multifunctional nanocomposites based on tetraethelenepentamine modified graphene oxide/epoxy. J Mater Sci 48:7883-7892

39. Zaman I, Manshoor B, Khalid A, Meng Q, Araby S (2014) Influence of interface on epoxy/clay nanocomposites: mechanical and thermal dynamic properties. J Mater Sci 49:5856-5865

40. Qi B, Yuan Z, Lu S, Liu K, Li S, Yang L, Yu J (2014) Mechanical and thermal properties of epoxy composites containing graphene oxide and liquid crystalline epoxy. Fiber Polym 15(2):326-333 
41. Mishra S, Verma J (2016) Thermal decomposition kinetics of silane treated wood: PVC microcellular composites. Int J Plast Technol 20(1):93-105

42. Mishra S, Verma J (2016) Effect of treatment of Tioz on thermal decomposition kinetics of wood: PVC microcellular composites, Int $\mathbf{J}$ Plast Technol. doi:10.1007/s12588-016-9165-0

43. Mishra S, Shimpi NG, Mali AD (2011) Influence of stearic acid treated nano- $\mathrm{CaCO}_{3}$ on the properties of silicone nanocomposites. J Polym Res $18: 1715-1724$ 